\title{
e-Math Workshops: a Forum for Exchanging Experiences of Mathe- matics e-Learning at University Level
}

Antonio F. Costa (UNED, Madrid, Spain), Fernando P. da Costa (UAb, Lisbon, Portugal), Maria Antonia Huertas (UOC, Barcelona, Spain)

We report here about a series of international workshops on e-learning of mathematics at university level, which have been jointly organised by the three publicly funded open universities in the Iberian Peninsula and which have taken place annually since 2009 . The history, achievements and prospects for the future of this initiative will be addressed.

\section{Introduction}

Distance learning already has a long and remarkably successful history in enabling access to higher education for populations that, for whatever reasons, are not able to attend classes at a traditional institution [1].

Distance learning programmes have always been dependent on the most up-to-date communication technology of the day, from the widespread generalisation of regular mail distribution using the rail network in 19th century Europe, which was the underpinning of the "correspondence courses" phase of distance learning, to the use of radio and television capabilities in the 20th century, to the use of electronic mail at the turn of the millennium, until the present day internet based e-learning platforms for teaching online.

These technological changes in distance learning have naturally implied a corresponding change in the way materials in the various disciplines are produced and presented to students. In the case of mathematics, the ongoing pace of change in information, communication and computing technologies, with a strong impact in the newly available informatics tools, also requires a constant actualisation in technological and pedagogical issues from mathematicians teaching at universities offering online courses, either completely (e-learning) or partially (blearning). These actualisation requirements have resulted in a number of initiatives aimed at fostering the interaction and exchange of experiences between them.

\section{e-math workshops and online learning of mathematics in Spain and Portugal}

The Iberian Peninsula has three state funded universities entirely dedicated to offering online courses: in Spain the Universidad Nacional de Educación a Distancia (with its central site in Madrid, founded in 1972) and the Universitat Oberta de Catalonia (in Barcelona, founded in 1995) and in Portugal the Universidade Aberta (in Lisbon, founded in 1988). In spite of the close geographical proximity (about 1,000 kilometres separate Lisbon and Barcelona, with Madrid almost exactly in the middle), the fact is that close collaboration between mathematicians of our three universities only started after we met for the first time while attending the 5th JEM Workshop - "ICT on the Teaching of Mathematics and on the Mathematics Curriculum" in Paris, organised in November 2008 by the late Mika Seppälä [2].

The recognition of common challenges facing the teaching of university mathematics over the internet and the need for learning from each other's experiences, both from the successes and the failures, led us to start a regular series of meetings, jointly organised by our three universities, the first of which took place in Lisbon, at UAb, in the Summer of 2009. The success of this first meeting resulted in the organisation of the next two meetings, in Madrid (2010) and Barcelona (2011). At this stage, the name of these annual meetings finally stabilised to "emath workshops". The cyclic nature of the organisation of the meetings has been maintained and last May the meeting achieved the middle of its third cycle with the organisation of the 8th meeting in Madrid.

Mathematical e-learning has important specific characteristics implying particular use of technology and educational strategies. Therefore, the subjects in the meetings include news on the technology of mathematical communication, innovations in mathematical e-learning strategies, assessment technology, educational data analysis, videos, MOOCS, good educational practices, student results presentations, programmes and tools for teaching mathematics and many, many more.

\section{e-math workshops as an international maths e-learning forum}

Although the origin of the e-math workshops was the desire to exchange experiences about e-learning of mathe-
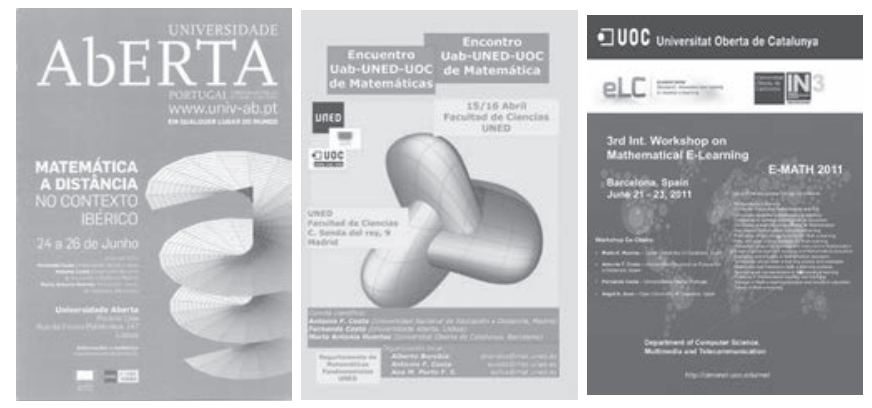

Posters of the first three meetings on e-learning of mathematics, jointly organised by UAb, UNED and UOC and held in Lisbon (June 2009), Madrid (April 2010) and Barcelona (June 2011) 
matics in our three Iberian distance learning universities, from the very beginning we were aware that our collaboration must not lack attention to what was going on in other educational institutions in our countries, and to the developments of mathematics e-learning in Europe and the world beyond the Pyrenees.

A reflection of this awareness is the inclusion of invited guest speakers to the workshops from outside Spain and Portugal: Hans Cuypers (Eindhoven University of Technology, the Netherlands), Sven Trenholm (Loughborough University, UK), Miryam Berezina (Ort Braude College, Israel) Kellie Grasman (Missouri University of Science and Technology, USA) and Karan Sagar (Massachusetts Institute of Technology, USA) in Barcelona, 2011; David Brannan (Open University, UK) in Lisbon, 2012; Magally Martínez Reyes and René Cruz Flores (Universidad Autónoma del Estado de México) and Olga Caprotti (Project Manager of the Thematic Network: Joining Educational Mathematics) in Madrid, 2013; and Mika Seppälä (University of Helsinki, Finland) in Barcelona 2014, by videoconference.

Another indication of the openness of the e-math workshops to the wider mathematical community is that they continue to attract participants from other institutions of both our countries that use and develop online teaching tools as an aid to their more traditional face-toface teaching. Some of those who have presented oral communications are José Antonio Seijas (Universidade da Coruña, Spain), José Santos and Alexandre Trocado (Instituto GeoGebra de Portugal), Juan Medina (University of Cartagena, Spain), Juan Moreno García (UDIMA - Universidad a Distancia de Madrid, Spain), Laura Bujalance (Universidad Camilo José Cela, Spain), Marta Ginovart and Mónica Blanco (Polytechnic University of Catalonia, Spain), Rui Paiva (Leiria Polytechnic, Portugal) and Ruy Costa (Universidade Nova de Lisboa, Portugal). In several meetings, we have also had participation from scientists in areas such as physics, chemistry and economy (e.g. $\mathrm{M}^{\mathrm{a}}$ Isabel Gómez del Rio, Chemistry of UNED, Madrid, 2013). And, of course, there have been many who, although not presenting, have attended the talks and contributed to the discussions. There have also been participants with interests in other educational levels, including secondary schools, adult access to uni-

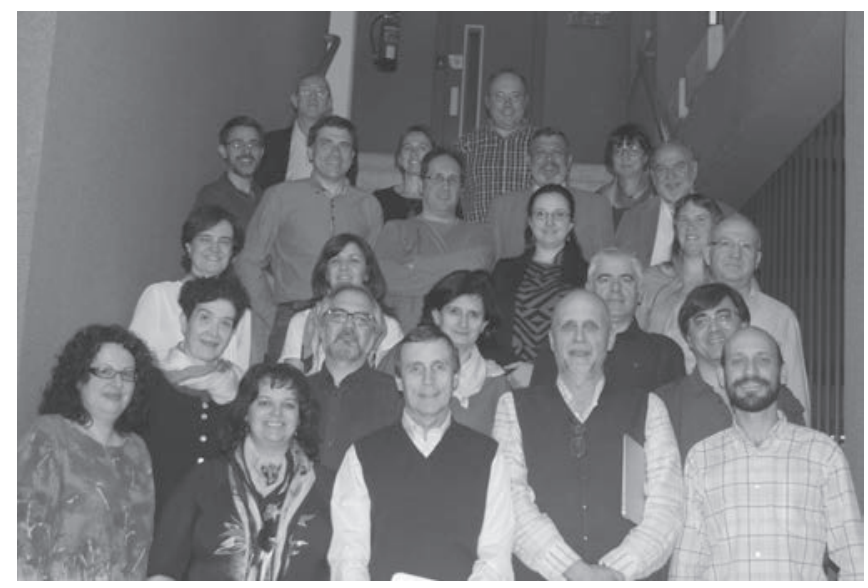

Participants at the 8th e-math workshop, Madrid (May 2016) versity, lifelong learning and permanent teacher training, revealing the importance of e-learning methodology in teaching mathematics.

On another level, the e-math workshops have also attracted the interest of a technological company dedicated to mathematical e-learning activity - Wiris (Maths and More, Barcelona), with representatives present at most of our meetings and talks by Carles Aguiló and Ramón Eixarch.

Last but not least, an extended dossier on "Mathematical e-Learning", with papers directly related to the 3rd e-math workshop, has been published in the "Universities and Knowledge Society Journal" [3].

\section{e-math impacts and future prospects}

In addition to the important aspects of exchanging ideas, practices and experiences on how to teach mathematics online, there have been a number of other tangible consequences of the e-math meetings. A major one is the supervision of students for Master's degrees and PhDs. Several MSc students have worked for their dissertations under the supervision of professors of one of the other universities, using for that accompanying work the technological tools pertaining to distance learning. Another type of collaborative initiative between teaching staff of UAb, UOC and UNED has also taken place, with postgraduate (MSc and $\mathrm{PhD}$ ) courses and lifelong learning programmes of one of the universities being taught through an online platform by a professor of another, with no need for them to leave their office. Distance learning can also serve students through "delocalisation" of instructors, who, like the students themselves, can be located anywhere in the world and still be effective in their teaching roles!

Due to the support of a number of financing sources, among them an Erasmus + Agreement, some of the students involved in the joint supervision effort have afterwards been able to present their work at later e-maths meetings, which, in this way, have also provided future mathematicians a way to gain experience in communicating their new results.

All e-math conferences conclude in a round table about possible collaborations and, on all occasions, new ideas arise, some turning into a reality by the time of the next meeting.

In the last two e-math workshops (Porto 2015 and Madrid 2016), we have been happy to have the organisational support of the Real Sociedad Matemática Española, the Societat Catalana de Matemàtiques and the Sociedade Portuguesa de Matemática, who all provided remarkable help in spreading information about the workshops to their associates and to the Iberian public at large. To bring e-math to the attention of a wider European constituency is one of the goals of this paper, and the natural role of the European Mathematical Society in supporting this objective is, we believe, invaluable.

\section{References}

[1] B. Holmberg: The Evolution, Principles and Practices of Distance Education, Studien und Berichte der ArbeitsstelleFernstudien- 
forschung der Carl von Ossietzky Universitat Oldenburg, Band 11, BIS-Verlag der Carl von Ossietzky Universitat Oldenburg, Oldenburg, 2005.

[2] JEM-Joining Educational Mathematics: eContentPlus Thematic Network: http://webalt.mobi/jem/index.html.

[3] Juan, Ángel A.; Huertas, María Antonia; Cuypers, Hans; Loch, Birgit eds. (January 2012). "Mathematical e-learning". Universities and Knowledge Society Journal (RUSC). Vol. 9, No. 1, ISSN 1698-580X. http://dx.doi.org/10.7238/rusc.v9i1.1431.

\section{Annex: internet addresses of past e-math workshops}

4th e-math, Lisbon 2012:

https://sites.google.com/site/4emath2012/

5th e-math, Madrid 2013:

https://sites.google.com/site/5emath2013madrid/

6th e-math, Barcelona 2014:

http://www.uoc.edu/portal/en/symposia/emath_2014/

7th e-math, Porto 2015:

https://sites.google.com/site/7themath2015/

8th e-math, Madrid 2016:

https://sites.google.com/site/8emath2016madrid/

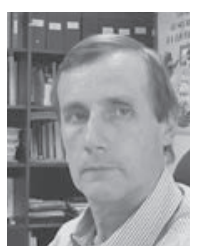

Antonio F. Costa [acosta@mat.uned.es] teaches at the Department of Matemáticas Fundamentales, UNED, Madrid, and is Vice-Dean of Mathematics and Scientific Research at the Facultad de Ciencias, UNED. His research interests are Riemann and Klein surfaces, particularly moduli spaces. He is an academic correspondent of Real Academia de Ciencias Exactas, Fisicas y Naturales of Madrid and, at the moment, is the coordinator of the thematic network Red Española de Topología.

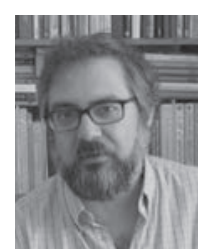

Fernando P. da Costa [fcosta@uab.pt] teaches at the Department of Sciences and Technology of Universidade Aberta, Lisbon, and is a researcher at the Centro de Análise Matemática, Geometria e Sistemas Dinâmicos, Instituto Superior Técnico, University of Lisbon, Portugal. His research interests are analysis and differential equations, particularly dynamical aspects. He received his PhD at Heriot-Watt University, Edinburgh, in 1993. He was VicePresident of the Portuguese Mathematical Society from 2012 to 2014 and President from September 2014 until August 2016.

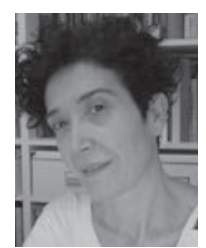

Maria Antonia Huertas [mhuertass@uoc. edu] teaches at the Department of Computer Science of Universitat Oberta de Catalunya, Barcelona. She is currently leading the Technology-Enhanced Knowledge and Interaction Group (TEKING) at the e-learn centre (UOC) in Barcelona, Spain. Her research interests include logic, knowledge representation, technology enhanced learning and mathematical e-learning. She is organiser of the annual workshops on TechnologyEnhanced Assessment, Analytics and Feedback (TEAAF) and takes part in several interest groups on mathematical education. 